\title{
Enhanced Efficiency of TaON and BiOI-based Solar Cells by Au Nanoparticles
}

\author{
B. Ahmmad*, J. Kurawaki, K. Leonard, and Y. Kusumoto \\ Department of Chemistry and Bioscience, Graduate School of Science and Engineering \\ Kagoshima University, 1-21-35 Korimoto, Kagoshima 890-065, Japan
}

Received 11 May 2010, accepted 16 July 2010

\begin{abstract}
$\mathrm{Au}$ nanoparticles were prepared by a chemical reduction method and were deposited on $\mathrm{TaON}$ nanoparticle or $\mathrm{BiOI}$ microsphere to prepare the composites of $\mathrm{Au} / \mathrm{TaON}$ or $\mathrm{Au} / \mathrm{BiOI}$, respectively. The composites of $\mathrm{Au} / \mathrm{TaON}$ and $\mathrm{Au} / \mathrm{BiOI}$ were analyzed by UV-visible spectroscopy, XRD, and EDX. The films of these nanocomposites were prepared by a squeeze method and were applied to solar cell where Pt film was used as counter electrode. A water based solution of $\mathrm{Ce}^{3+} / \mathrm{Ce}^{4+}$ was used as an electrolyte. It was found that $\mathrm{Au}$ deposited $\mathrm{TaON}$ or $\mathrm{BiOI}$ film shows higher current $(I)$-voltage $(V)$ curve under UV-visible light irradiation.
\end{abstract}

Keywords: Au; TaON; BiOI; Composite; Solar cell.

(C) 2010 JSR Publications. ISSN: 2070-0237 (Print); 2070-0245 (Online). All rights reserved.

DOI: $10.3329 /$ jsr.v2i3.5000 J. Sci. Res. 2 (3), 413-417 (2010)

\section{Introduction}

Semiconductor photocatalysts offer a potential approach for the conversion of solar energy conversion. Among various metal oxide semiconductors $\mathrm{TiO}_{2}$ has been widely studied. But it shows photoactivity only under UV light which accounts for merely $<5 \%$ of the solar photons, thereby hampering its wide usages. There are many other promising oxide and nonoxide semiconductors which shows photoactivity under visible light such as $\mathrm{WO}_{3}, \mathrm{Fe}_{2} \mathrm{O}_{3}$, $\mathrm{CdS}, \mathrm{Bi}_{2} \mathrm{~S}_{3}, \mathrm{In}_{2} \mathrm{~S}_{3}, \mathrm{Ta}_{3} \mathrm{~N}_{5}$, TaON etc $[1,2]$. Among these catalysts, TaON, which has a bandgap of $2.5 \mathrm{eV}$ (absorption edge at $500 \mathrm{~nm}$ ), has conduction and valence band edges of ca. -0.3 and $+2.2 \mathrm{~V}$ versus $\mathrm{NHE}(\mathrm{pH}=0)$, respectively, sufficient for splitting water into $\mathrm{H}_{2}$ and $\mathrm{O}_{2}$ [3]. But merely TaON films show low photo to current conversion efficiency in solar cell.

\footnotetext{
*Correspoding author: b.ahmmad5@gmail.com
} 
Recently a new class of bismuth oxyhalide photocatalysts have been reported and among them $\mathrm{BiOI}$ was found to show higher photocatalytic activity than $\mathrm{TiO}_{2}$ under visible light irradiation [4]. Zhao et.al. [5] prepared BiOI microsphere particles and showed application to solar cell for the first time [5]. However, the efficiency of the solar cell was low for practical application. For the enhancement of the activity, encapsulation or adoration of semiconductor photocatalysts with highly dispersed noble metal nanoparticles such as Ag, $\mathrm{Au}$ and $\mathrm{Pt}$ are of great interest, because the nanoscale noble metals are usually a classic highperformance heterogeneous catalyst $[6,7]$. Especially, the nanoparticles of gold have been attracting more attention because it has many color varieties in the visible region based on plasmon resonance, which is due to the collective oscillations of the electrons at the surface of the nanoparticles. The resonance wavelength strongly depends on the size and shape of the nanoparticles, the interparticle distance, and the dielectric property of the surrounding medium. So far, enhanced photocatalytic activities of $\mathrm{TaON}$ and $\mathrm{BiOI}$ by $\mathrm{Au}$ nanoparticles have not been reported. Here we report the successful preparation of $\mathrm{Au} / \mathrm{TaON}$ and $\mathrm{Au} / \mathrm{BiOI}$ nanocomposites by a simple method and their applications in solar cells.

\section{Experimental}

TaON was received as a gift from the University of Tokyo [3] and BiOI nanoplate microspheres were prepared by a solvothermal method [8]. The colloidal Au nanoparticles were prepared by the citrate reduction [9] from chloroauric acid (Wako Pure Chemical Industries, Ltd., Japan). The $\mathrm{Au}$ nanoparticles were condensed by using a high speed centrifugation machine running at $15000 \mathrm{rpm}$ for $20 \mathrm{~min}$ and mixed with $300 \mathrm{mg}$ of TaON or $\mathrm{BiOI}$ followed by sonication for $5 \mathrm{~min}$. Finally, $\mathrm{Au}$ deposited $\mathrm{TaON}$ or BiOI was dried at 40 ${ }^{\circ} \mathrm{C}$. Chitosan solution was prepared by mixing chitosan flakes (Wake, 98\%) with water and gradually dropping $\mathrm{HCl}$ solution to the mixture to maintain the $\mathrm{pH}$ near 3. After removal of the undissolved part, the $\mathrm{pH}$ value of chitosan solution was adjusted to about 5.0 by using an aqueous $\mathrm{NaOH}$ solution. The final concentration of chitosan solution was estimated to be 0.5 wt $\%$.

For the preparation of the $\mathrm{BiOI}$ electrodes, $\mathrm{BiOI}$ nanoplate microspheres were dispersed in chitosan solution to form a $10 \mathrm{mg} / \mathrm{mL}$ solution and ultrasonicated for $5 \mathrm{~min}$, and $0.3 \mathrm{~mL}$ of the colloidal solution was dropped on the pretreated ITO surface and allowed to dry at $50^{\circ} \mathrm{C}$ for $24 \mathrm{~h}$. Both films of $\mathrm{Au} / \mathrm{TaON}$ and $\mathrm{Au} / \mathrm{BiOI}$ were used as a working electrode and Pt-based films were used as a counter electrode. The two electrodes were sandwiched and a mixture of $\mathrm{Ce}\left(\mathrm{NO}_{3}\right)_{3} \cdot 6 \mathrm{H}_{2} \mathrm{O}(0.1 \mathrm{M}$, wako, $99 \%)$ and $\mathrm{Ce}\left(\mathrm{NO}_{3}\right)_{4}(0.05 \mathrm{M}$, Sigma-aldrich, $99 \%)$ in a water based solution (35\% ethanol and $65 \%$ water) was used as an electrolyte that was filled into a space between the two electrodes. All films were prepared on indium-tin-oxide (ITO, Aldrich) coated glasses which have a resistance of 8-12 ohms.

The UV-visible diffuse reflectance spectra of the photocatalysts were recorded using a UV-visible spectrophotometer (Shimadzu Corporation, MPS-2000) and $\mathrm{BaSO}_{4}$ as a reflectance standard. The size and surface condition of the submicrospheres were analyzed by a field-emission scanning electron microscope (FE-SEM, Hitachi, S-4100H) and a transmission electron micrograph (JEOL, JEM-3010 VII, operating at $300 \mathrm{kV}$ ). Crystal 
structure identification was made by X-ray diffraction (XRD) using a PANalytical Advance $\mathrm{X}$-ray diffractometer with $\mathrm{CuK} \alpha$ radiation. The XPS patterns were recorded on an X-ray photoelectron spectrometer (Shimadzu, ESCA-1000) using MgK $\alpha$ X-ray as the excitation source and $\mathrm{C} 1 \mathrm{~s}(284.6 \mathrm{eV})$ as the reference line. The quantitative chemical composition of the $\mathrm{Au} / \mathrm{TaON}$ and $\mathrm{Au} / \mathrm{BiOI}$ composite nanocluster surface was also measured using an energy dispersive X-ray spectrometer (EDX, Philips, XL 30CP) attached to the cold field SEM.A xenon lamp (Inotex 300-W LX-300F) with an IR cut- off filter was used as a light source (power 1 sun). For the measurement of the performance of solar cell, an $I-V$ meter (Keithly 2400) was used. The $I-V$ meter was connected to a computer with a Peccell $I-V$ curve analyzer (PECK2400-N).

\section{Results and Discussion}

Fig. 1(a) shows the TEM images of Au nanoparticles prepared by the citrate reduction method. It is seen that most of the particles have spherical shape. The average diameters of the gold nanoparticles were about $20 \mathrm{~nm}$.
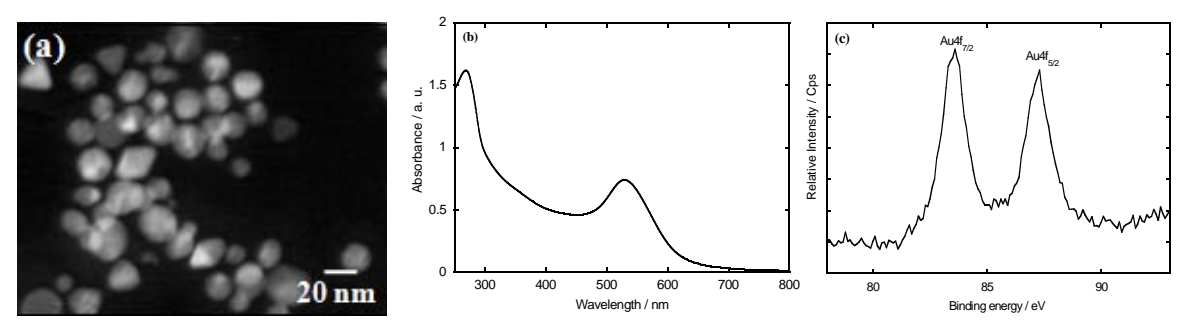

Fig. 1. (a) TEM image, (b) UV-visible reflection spectrum, and (c) XPS spectrum of Au nanoparticles.

The UV-visible spectrum of the prepared gold nanoparticles show a strong absorption peak at $530 \mathrm{~nm}$ for spherical gold nanoparticles (Fig. 1b). The X-ray photoelectron spectroscopy (XPS) was used to study for the surface composition and electronic states of the gold nanoparticles. Fig. 1c shows the typical gold XPS spectrum of $4 \mathrm{f}$ orbital in the as-deposited film. The spectrum shows the peaks at binding energies of $A u 4 f_{7 / 2}$ at 83.8 and $\mathrm{Au}_{4 / 2}$ at $87.45 \mathrm{eV}$ corresponding to the standard gold [9] the former of which is also found to be significantly different from $\mathrm{Au}^{+} 4 \mathrm{f}_{7 / 2}(84.6 \mathrm{eV})$ and $\mathrm{Au}^{3+} 4 \mathrm{f}_{7 / 2}(87.0 \mathrm{eV})$ but similar to $\mathrm{Au}^{0} 4 \mathrm{f}_{7 / 2}(84.0 \mathrm{eV})$. The XPS results suggest that the Au species are present in the metallic state and their surfaces have no charge.

Fig. 2(a, b) shows the representative scanning electron microscopy (SEM) images of BiOI and $\mathrm{TaON}$ films. The particle sizes of $\mathrm{TaON}$ ranges from $200 \mathrm{~nm}$ to $300 \mathrm{~nm}$. The as-prepared BiOI sample consists of spherical particles with size of 2-5 $\mu \mathrm{m}$. The higher magnification SEM image (data not shown) revealed that the BiOI spherical particles are composed of nanoplates of about several nanometers in thickness. The nanoplates were aligned radically and tightly to further form hierarchical microspheres. 

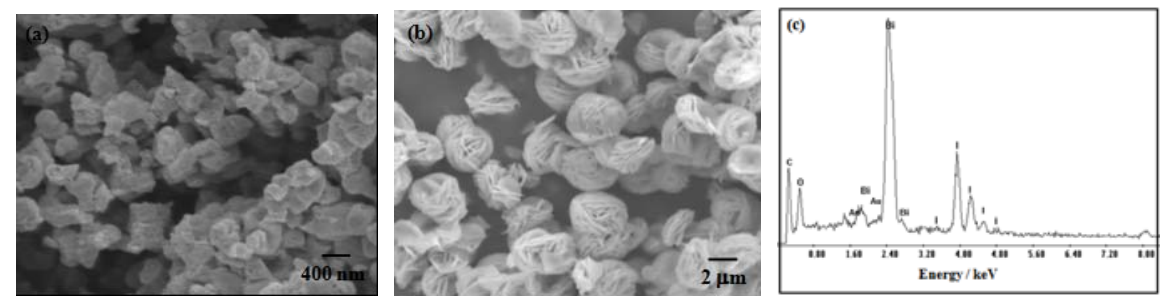

Fig. 2. (a) FE-SEM images of TaON nanoparticles, (b) BiOI nanoplate microspheres, and (c) EDX spectrum of $\mathrm{Au} / \mathrm{BiOI}$ composites.

The EDX analysis was employed to obtain the quantitative information on the amount and the distribution of $\mathrm{Au}$ and $\mathrm{TaON}$ or BiOI species in the sample. Fig. 2c shows the EDX spectrum of $\mathrm{Au} / \mathrm{BiOI}$ composite showing the presence of $\mathrm{Bi}, \mathrm{O}, \mathrm{I}, \mathrm{Au}$ and the carbon peak appears from the carbon tape used for sampling. Similarly EDX analysis was performed for $\mathrm{Au} / \mathrm{TaON}$ composite and it showed the presence of $\mathrm{Ta}, \mathrm{O}, \mathrm{N}$ and $\mathrm{Au}$ only (data not shown). It was found that the amounts of $\mathrm{Au}$ in $\mathrm{BiOI}$ or $\mathrm{TaON}$ are 1.9 and $1.7 \mathrm{wt} \%$, respectively.

The UV visible reflection spectra of various composites are shown in Fig. 3 (a). It is seen that $\mathrm{TaON}$ and $\mathrm{BiOI}$ have adsorption edges at 500 and $650 \mathrm{~nm}$, respectively. Au deposited $\mathrm{TaON}$ shows two peaks at 500 and $530 \mathrm{~nm}$. The peak appeared at $530 \mathrm{~nm}$ is due to the light absorption by $\mathrm{Au}$ nanoparticles. However, in case of $\mathrm{Au} / \mathrm{BiOI}$ nanocomposite the absorption peak of $\mathrm{Au}$ is overlaid by that of BiOI.
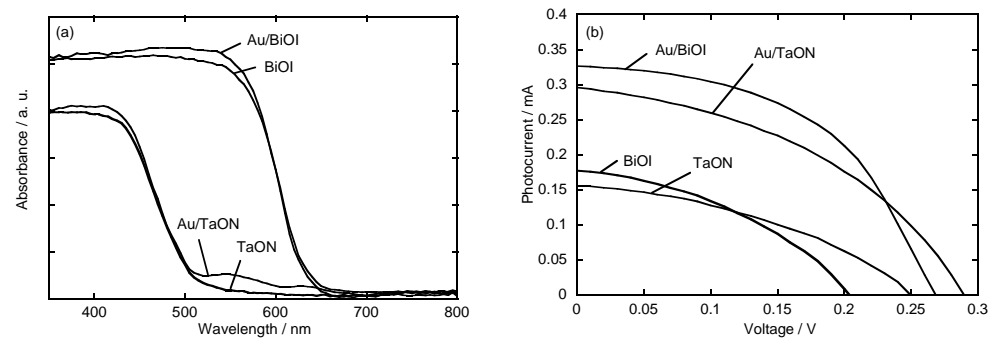

Fig. 3. (a) $\mathrm{UV}$-visible reflection spectra of $\mathrm{TaON}, \mathrm{BiON}, \mathrm{Au} / \mathrm{TaON}$, and $\mathrm{Au} / \mathrm{BiOI}$, (b) and $\mathrm{I}-\mathrm{V}$ curve analysis of $\mathrm{TaON}, \mathrm{BiON}, \mathrm{Au} / \mathrm{TaON}$, and $\mathrm{Au} / \mathrm{BiOI}$ based solar cells.

The characteristics of I-V curves of TaON, BiOI, $\mathrm{Au} / \mathrm{TaON}$, and $\mathrm{Au} / \mathrm{BiOI}$-film solar cells are shown in Fig. 3b. It is seen that the open circuit voltage is higher for the TaON -based solar cell but the closed circuit current is higher in case of the BiOI-film solar cell. These differences arise from the different band positions, light absorption ability of the semiconductor materials [10]. Also, it was found that the solar cells composed of $\mathrm{Au} / \mathrm{TaON}$ or $\mathrm{Au} / \mathrm{BiOI}$ films had higher photon to current conversion efficiency. In case of $\mathrm{TaON}$ the 
absorption edge is shifted to the longer wavelength due to the presence of Au nanoparticle as seen from UV visible spectra. But the absorption wavelength of Au nanoparticle is overlaid by the aborption edge of BiOI. It can be concluded that in both cases Au nanoparticles absorb light and transfer electron to the semiconductor material which helps to enhance the efficiency of the solar cells.

\section{Conclusion}

The performance of $\mathrm{TaON}$ and $\mathrm{BiOI}$ based solar can be enhanced by $\mathrm{Au}$ nanoparticles. However, the amount of Au nanoparticles could not be controlled by the present method and the amount of Au nanoparticles was too low. It is expected that if the amount of deposited $\mathrm{Au}$ nanoparticles deposited on $\mathrm{TaON}$ or BiOI could be increased, the performance of the solar cell will also be increased. Further research is underway in our laboratory.

\section{Acknowledgements}

We gratefully acknowledge Japan Society for the Promotion of Science (JSPS) for the postdoctoral fellowship award to B.A. This work was partly supported by Grand-in-Aid for Scientific Research (B) (No. 19360367) and Grant-in-Aid for JSPS Fellows (No.20.08081). The authors also wish to thank Prof. Kazunari Domen of Department of Chemical System Engineering, The University of Tokyo, for kindly providing TaON.

\section{References}

1. A. B. Murphya, P. R. F. Barnesa, L. K. Randeniyaa, I. C. Plumba, I. E. Greyb,M. D. Horneb, and

2. N. Barreau, Sol. Energ. 83, 363 (2009). doi:10.1016/j.solener.2008.08.008

3. M. Hara, T. Takata, J. N. Kondo, and K. Domen, Catal. Today 90, 313 (2004). doi:10.1016/j.cattod.2004.04.040

4. W. Wang, F. Huang, and X. Lin, J. Yang, Catal. Commun. 9, 8 (2008). doi:10.1016/j.catcom.2007.05.014

5. K. Zhao, X. Zhang, and L. Zhang, Electrochem. Commun. 11, 612 (2009). doi:10.1016/j.elecom.2008.12.041

6. R. Ma, T. Sasaki, and Y. Bando, J. Am. Chem. Soc., 126, 10382 (2004). doi:10.1021/ja048855p

7. Y. Tian and T. Tatsuma, J. Am. Chem. Soc. 127, 7632 (2005). doi:10.1021/ja042192u

8. X. Zhang, Z. Ai, F. Jia, and L. Zhang, J. Phys. Chem. C 112, 747 (2008). doi:10.1021/jp077471t

9. M. Abdulla-Al-Mamun, Y. Kusumoto, A. Mihata, M. S. Islam, and B. Ahmmad, Photochem. Photobiol. Sci. 8, 1125 (2009). doi:10.1039/b907524k

10. M. Grätzel, Energy Resources Through Photochemistry and Catalysis (eds.) (Academic Press, New York, 1983). 